\begin{tabular}{|l|l|l|}
\hline & ESCOLA DE \\
PUCRS & HUMANIDADES & $\begin{array}{l}\text { Educação por escrito, Porto Alegre, v. 11, n. 1, p. 1-16, jan.-jun. 2020 } \\
\text { e-ISSN: 2179-8435 }\end{array}$ \\
\hline do http://dx.doi.org/10.15448/2179-8435.2020.1.32684 & \\
\hline
\end{tabular}

SEÇÃO ARTIGOS

\title{
Formação pedagógica de docentes e pós-graduandos no âmbito da Pós-Graduação em Fisiologia no Brasil
}

\author{
Pedagogical training of faculty and graduate students at Physiology Graduate \\ Programs in Brazil
}

\section{Maria Flavia Marques \\ Ribeiro ${ }^{1}$}

orcid.org/0000-0002-2265-7332 mflavia@ufrgs.br

\section{Gislaine Alves de \\ Oliveira $^{1}$ \\ orcid.org/0000-0001-9303-1858 gislaine.oliveira@ufrgs.br}

\section{Elaine Turk Faria ${ }^{1}$}

orcid.org/0000-0002-0288-655X

elainetfaria@hotmail.com

Recebido em: 11 dez. 2018 Aprovado em: 8 jan. 2020. Publicado em: 27 jul. 2020
Resumo: Embora a produção científica seja meta prioritária nas políticas públicas para a Pós-Graduação, a atividade profissional dos pós-graduandos envolverá sua atuação como docente. Os objetivos deste estudo foram investigar como ocorre a formação pedagógica dos docentes e pós-graduandos e identificar a opinião da comunidade acadêmica dos Programas de Pós-Graduação em Fisiologia sobre a qualidade e a importância dessa formação. Foram analisadas as respostas de 273 pós-graduandos, 89 docentes e 11 coordenadores a questionários eletrônicos. Os docentes consideram sua formação inicial boa, $67 \%$ participaram apenas uma vez ou não participaram de atividades de formação continuada e $95 \%$ dos docentes considera satisfatória sua atuação docente. As atividades de formação pedagógica dos pós-graduandos mais citadas foram estágios supervisionados, acompanhamento de professores em disciplinas e auxilio em aulas práticas. A avaliação positiva dos alunos sobre sua formação pedagógica cai de $78 \%$ no início do mestrado para $60 \%$ no final do doutorado. Conclui-se que a atividade docente e a formação pedagógica dos pós-graduandos parecem ser consideradas importantes, porém há pouca valorização da formação continuada dos docentes. É imprescindivel que a comunidade acadêmica faça uma reflexão sobre as prioridades e objetivos da formação no âmbito da Pós-Graduação.

Palavras-chave: Fisiologia. Ensino superior. Formação de professores. Pós-graduação.

Abstract: Although scientific production is a priority goal in public policies for Graduate Programs, the professional activity of graduate students will involve teaching activities. This study aimed to investigate how pedagogical training of teachers and graduate students occurs and to identify the opinion of the academic community of Physiology Graduate Programs about the quality and importance of pedagogical training. It was analyzed responses from 273 graduate students, 89 teachers and 11 coordinators to an electronic questionnaire. Faculty consider their initial training to be good, $67 \%$ participated only once or did not participate in continuing education activities and $95 \%$ of faculty consider their teaching performance satisfactory. The most mentioned pedagogical training activities of the graduate students were supervised internships and supporting teachers in courses and practical classes. The positive evaluation of the students about their pedagogical training falls from $78 \%$ at the beginning of the masters to $60 \%$ at the end of the doctorate. It is concluded that teaching activity and pedagogical training of the graduate students seems to be considered important, but there is little appreciation of the faculty continuous pedagogical training. It is imperative that the academic community reflect on the priorities and objectives of the graduate training.

Keywords: Physiology. Higher education. Teacher training. Graduate studies.

\section{(c) (1)}




\section{Introdução}

A necessidade de pesquisar como se dá a formação pedagógica em Programas de PósGraduação surge do fato de que grande parte dos docentes que atuam no Ensino Superior são formados em Programas de Pós-Graduação, mas não há exigência de formação pedagógica para os pós-graduandos. No presente estudo, será abordada a formação pedagógica de professores de uma área básica da Saúde e que se dedicam à docência universitária em instituições públicas. A maioria dos professores não são oriundos de licenciaturas e não possuem formação didáticopedagógica em seus cursos de Graduação e de Pós-Graduação. Nesse contexto, como é seu desempenho como docente? Como a formação pedagógica é vista pelos pós-graduandos, docentes e coordenadores? O que pensa a comunidade acadêmica sobre a importância da atividade docente no ensino?

A Fisiologia é o ramo das Ciências Biológicas que estuda as múltiplas funções dos sistemas orgânicos dos seres vivos e os diferentes mecanismos responsáveis por sua regulação. Em sintese, a Fisiologia estuda o funcionamento dos organismos e a manutenção da saúde dos mesmos. Os conhecimentos de áreas próximas, como Bioquímica, Farmacologia, Histologia, Biologia Celular e Molecular, e outras, se relacionam intimamente com os de Fisiologia. Por isso, embora a proposta deste trabalho seja investigar apenas a área de Fisiologia, certamente a indagação poderia se estender para as outras Ciências Biológicas e, possivelmente, para muitas outras áreas do conhecimento, se não todas. Estas áreas básicas abordam temas que são ministrados para os cursos da área da Saúde, Ciências Biológicas, Ciências Agrárias e outras, o que envolve aproximadamente, em todo o Brasil, 4.625 cursos da área da Saúde, 732 de Ciências Biológicas e 379 de Agrárias (INEP, 2017).

Os conhecimentos abordados pela Fisiologia são fundamentais para o sucesso de profissionais da Saúde, uma vez que compreender como funciona o organismo normal é a base para entender quando algo não funciona bem e que procedimentos terapêuticos seriam adequados para buscar o retorno à saúde. Por ser um conteúdo complexo, que exige conhecimentos prévios, envolve inúmeros conceitos, raciocínio lógico e integrativo e capacidade de fazer relações entre os conteúdos (COLTHORPE et al., 2018), a maioria dos estudantes considera que este tema é difícil e requer um grande esforço cognitivo (MICHAEL, 2007). Dessa forma, ensinar e aprender Fisiologia representa um desafio para estudantes e docentes, que muitas vezes não estão preparados para enfrentá-lo com sucesso.

O professor universitário se insere em uma comunidade acadêmica "pressionada" devido a uma enorme exigência social e acadêmica, onde o docente recebe um grande número de encargos e deve desempenhar de forma satisfatória todos eles. Nesse contexto, muitas vezes o ensino é considerado uma atividade menos importante. Isso ocorre devido a uma desvalorização dentro da instituição, nas agências de fomento e, o que é mais grave, do próprio professor. Apesar da crescente especialização desses docentes, sua competência pedagógica tem sido questionada (QUADROS et al. 2012; PACHANE; PEREIRA, 2004). Os inúmeros relatos de insatisfação dos estudantes com o desempenho didático de seus professores reforçam a ideia de que sua atuação deixa a desejar (SILVEIRA, 2017; GIL, 2015).

A legislação que regulamenta a formação de professores para o Ensino Superior vigente é a Lei de Diretrizes e Bases implantada em 1996, na Lei 9.394. O Art. 66 refere-se à formação do professor universitário como responsabilidade de Programas de Pós-Graduação (PPGs), mas não há clara referência à necessidade de formação pedagógica desses docentes (BRASIL, 1996). Desde o surgimento dos primeiros cursos de Pós-Graduação, nas décadas de 1950 e 1960, junto com a criação da Coordenação de Aperfeiçoamento de Pessoal de Nivel Superior (CAPES) e do Conselho Nacional de Desenvolvimento Cientifico e Tecnológico (CNPq), a capacitação de docentes para o Ensino Superior é atribuição da Pós-Graduação.

As políticas públicas de Pós-Graduação no 
Brasil buscaram, inicialmente, capacitar os docentes das universidades, depois investiram no desempenho do sistema de Pós-Graduação e, finalmente, no desenvolvimento da pesquisa na universidade, pensando na pesquisa científica e tecnológica e no atendimento das prioridades nacionais (CAPES/PNPG). Há também uma tentativa de se pensar em modelos de qualificação de professores, mas essa questão é estritamente referente aos docentes da Educação Básica. A ideia de que o mestrado e/ou o doutorado capacitam o professor para atuar no Ensino Superior não é nova (PIMENTA; ANASTASIOU, 2002) e faz parte do senso comum da comunidade universitária e dos setores que planejam e regulam as politicas educacionais. No atual Plano Nacional de Educação (2014-2024), há metas de expansão de matrículas no Ensino Superior (meta 12), melhora da qualidade do Ensino Superior (meta 13), aumento do número de docentes com mestrado e doutorado e aumento do número de matriculas na Pós-Graduação stricto sensu (meta 14) (MEC/PNE). A única referência à formação de professores para o Ensino Superior no PNE é a meta de aumentar o número de mestres e doutores. Assim, a questão que se coloca é "A formação de mestres e doutores inclui atividades de modo a capacitá-los para exercer a docência"?

Os PPGs tendem a priorizar a formação de bons pesquisadores e, refletindo as exigências do sistema avaliativo da CAPES, acabam por não valorizar a formação pedagógica de seus alunos. Diferente do professor do Ensino de Nivel Médio, cuja formação pedagógica deve ser desenvolvida no curso de Licenciatura, o professor do Nivel Superior, embora sendo mestre e/ou doutor, nem sempre tem conhecimento das concepções de ensino e aprendizagem que o habilitem a exercer a docência com a mesma eficiência com que exerce sua profissão ou a investigação científica (VALENTE; VIANA, 2010). Os bacharéis que se tornam professores, procuram ensinar com os referenciais que possuem, em geral, o modo como foram ensinados. Assim, muitos modelos acabam sendo perpetuados na prática docente, sem que o mestre ou doutor tenha consciência das habilidades e conhecimentos que ele deveria dominar para se tornar um "professor profissional" e enfrentar com sucesso os enormes desafios da docência (TARDIF, 2002; BOLZAN; ISAIA, 2010; CARDOSO, 2016).

Os próprios professores do Ensino Superior desconhecem a necessidade de formação especifica para exercer a docência e apenas no final do século $X X$ iniciou-se um movimento de autocrítica, realizada pela comunidade acadêmica, quanto à formação docente (CORRÊA; RIBEIRO, 2013; CUNHA; DINIZ-PEREIRA, 2017), buscando desfazer a crença de que o professor universitário não precisa de formação pedagógica e contribuindo para a valorização da atividade docente e do Ensino Superior (PACHANE; PEREIRA, 2004; LOURENÇO et al., 2016).

Assim, o presente estudo busca conhecer o perfil e a formação dos docentes que atuam em Programas de Pós-Graduação em Fisiologia e como ocorre a formação pedagógica dos pósgraduandos, além de identificar a percepção da comunidade acadêmica sobre a qualidade e importância dessa formação.

\section{Metodologia}

Este estudo foi realizado a partir da coleta da opinião da comunidade acadêmica dos Programas de Pós-Graduação (PPGs) em Fisiologia do Brasil. O levantamento de dados foi realizado por questionários eletrônicos com perguntas fechadas, para obtenção da opinião dos agentes envolvidos na formação de professores de Fisiologia e na busca da compreensão de sua percepção sobre esse processo. Foram incluidos como sujeitos da pesquisa os alunos de mestrado e doutorado acadêmicos, matriculados no ano de 2015 em PPGs da área Ciências Biológicas II da CAPES - Fisiologia ou Ciências Fisiológicas, além dos coordenadores e docentes permanentes desses Programas. A partir de informações colhidas na Plataforma Sucupira - CAPES², foram 
identificados15 PPGs nesta área do conhecimento, dos quais participariam aproximadamente 340 docentes e 949 discentes de mestrado e doutorado. Para incluir os participantes no estudo, foi necessário solicitar a cada PPG o e-mail dos seus alunos e docentes. Dessa forma, cada participante recebeu um link associado ao seu e-mail, contendo o questionário eletrônico. Dos 15 PPGs selecionados para participar desta pesquisa, cinco não enviaram as informações necessárias dos docentes e discentes. Portanto, foram incluidos 10 PPGs, para os quais foram enviados 550 questionários aos pós-graduandos, 241 aos docentes e 14 aos coordenadores.

O sistema eletrônico que gerenciou o envio dos questionários e a computação das respostas foi o SurveyMonkey ${ }^{\circ}$. Esse sistema organiza as respostas objetivas e fornece o percentual de respostas em cada alternativa, além de permitir a estratificação da análise a partir de cada questão em particular e fazer relações entre as respostas de diferentes questões. Os questionários permaneceram disponiveis por 30 dias e foram reenviados uma vez, uma semana após o primeiro envio. No e-mail com o link enviado aos participantes havia uma breve descrição da pesquisa, com as informações sobre a confidencialidade e sigilo das informações obtidas, e a garantia de anonimato no tratamento dos dados. Foram incluidas no estudo apenas as respostas dos que concordaram em participar da pesquisa.

\section{Resultados e discussão}

O método escolhido para a coleta de dados, no presente estudo, foi o questionário eletrônico enviado via internet. O respondente recebia por e-mail um link único e intransferivel para acessar e responder ao questionário. O uso de questionários eletrônicos tem algumas vantagens e desvantagens (FALEIROS et al., 2016). Entre as vantagens está a facilidade de utilizar amostras grandes e atingir respondentes em locais distantes, praticidade para o respondente, o baixo custo e a velocidade de obtenção e processamento das informações. Entre as desvantagens, a principal é a baixa taxa de resposta aos questionários, sendo em alguns estudos de 7 a 13\%, enquanto em outros pode ser um pouco maior, chegando até $45,8 \%$ de respostas obtidos por Oliveira e Mello (2014). Algumas das razões da baixa taxa de resposta seria a dificuldade de conexão à internet, a percepção de spam, endereços eletrônicos não ativos e, principalmente, o assunto da pesquisa.

No presente estudo, foram respondidos 50,9\% (273) dos questionários enviados aos pós-graduandos, 36,7\% (89) dos enviados aos docentes e $78,6 \%$ (11) dos enviados aos coordenadores. Essas taxas são elevadas, mesmo considerando que os sujeitos desta pesquisa não são a população em geral, mas um grupo especifico de docentes e alunos de PPGs de uma área especifica e que, em tese, o assunto deveria ser de interesse de todos os sujeitos.

É preciso considerar também que 30\% dos PPGs não participaram da pesquisa por não terem fornecido os e-mails de seus alunos e professores. Pode-se supor que isso tenha ocorrido porque os Programas não deram importância à pesquisa proposta, por considerar que o tema da formação de professores não é relevante ou por não ter compreendido do que se tratava a pesquisa. Outra possibilidade é que não tenham recebido o e-mail que convidava a participar da pesquisa, ou não tenham lido com atenção. Apesar de não ser possivel interpretar com segurança o que de fato ocorreu, esses fatos podem indicar que a importância dada por esses coordenadores ao tema da pesquisa formação de professores - não foi suficiente para que vencessem seus receios e a possivel falta de tempo. O desprestigio do Ensino Superior na comunidade acadêmica, de maneira geral, é referendado pelas políticas governamentais e pela legislação atual, sendo que a formação pedagógica não parece constituir-se como um objeto de interesse para o campo cientíico, conforme já relatado por vários autores (VEIGA, 2005; CORREAA; RIBEIRO, 2013; PACHANE; PEREIRA, 2004).

As Instituições de Ensino Superior (IES) envolvidas nesta pesquisa são todas públicas, refletindo a maior concentração de PPGs nas IES públicas, assim como ocorre em outras áreas do conhecimento no Brasil. O conceito CAPES dos PPGs que participaram da pesquisa 
variou de 4 a 7 , sendo que $72 \%$ tinham conceito 4. Quanto à distribuição dos pós-graduandos que participaram deste estudo, 58,2\% (159) estavam no doutorado e 41,8\% (114) no mestrado, sendo que $53 \%$ estavam na primeira metade do curso e $47 \%$ na metade final.

Um dos objetivos principais deste trabalho foi determinar o perfil dos docentes, incluindo sua formação e sua percepção sobre essa formação e sobre sua atuação didático-pedagógica.

\section{Tempo de docência e formação inicial de docentes permanentes que atuam em Programas de Pós-Graduação de Fisiologia}

Para conhecer o perfil dos docentes que participaram do estudo, investigou-se há quanto tempo os professores exerciam atividades docentes no Ensino Superior. Observou-se que a maior parte dos docentes se encontra na faixa de 10 a 20 ou mais de 20 anos atuando como docentes no Ensino Superior (64\%). Considerando o longo caminho da carreira acadêmica, é natural que o percentual dos docentes com menos de 5 anos de docência seja menor (14,6\%). Porém, o percentual de $21,4 \%$ daqueles com 5 a 10 anos de docência indica que o processo de renovação está ocorrendo, o que é coerente com o grande número de novas contratações que ocorreram nas IES públicas nos últimos anos. O fato de 36,4\% dos docentes terem menos de 10 anos de docência pode ser um fator positivo, já que é possivel que o docente no início de carreira seja mais receptivo a inovações pedagógicas ou mesmo à reflexão sobre seu papel como professor. Vários elogiaram a iniciativa da realização desta pesquisa e solicitaram retorno com os resultados obtidos aqui, o que parece ser indicativo de boa receptividade ao assunto e revela a importância dada ao tema (dados não mostrados).

A formação inicial dos docentes envolve vários cursos de Graduação das áreas da Saúde, Ciências Biológicas e Agrárias. O curso de
Biologia (34.5\%) foi o que formou mais docentes que atuam nos Programas de Pós-Graduação estudados, seguido pelos cursos de Farmácia $(17,2 \%)$ e Biomedicina (10,3\%). Infelizmente, não foi perguntado se o curso era de licenciatura ou bacharelado, mas os únicos cursos que teriam essas opções seriam Biologia e Educação Física, o que corresponderia a, no máximo, 41,4\% dos docentes. Ainda sobre a formação inicial, 52,3\% dos professores foram formados em Cursos de Pós-Graduação de Fisiologia ou Ciências Fisiológicas, sendo Farmacologia o segundo mais frequente $(11,4 \%)$ e Biologia Molecular o terceiro (6,8\%). Os demais se distribuiram nas áreas afins, como Ciências Médicas, Ciências do Movimento, Psicobiologia e outras.

\section{Percepção dos docentes sobre a sua formação pedagógica inicial}

Ao serem perguntados sobre a percepção que tinham sobre a sua formação pedagógica nos cursos de Graduação, a maior parte dos docentes considera sua formação pedagógica boa (33.7\%) e $30,4 \%$ a considera muito boa ou excelente (Figura 1A). Esses dados tomados em conjunto, indicam que $64 \%$ dos docentes considera satisfatória sua formação didático-pedagógica na Graduação. Por outro lado, não é desprezivel o número de docentes (36\%) que declararam que não tiveram formação pedagógica na Graduação ou que essa foi fraca ou regular (Figura 1A).

Quanto à formação didático-pedagógica dos docentes nos cursos de Pós-Graduação, vemos que a avaliação positiva permanece sendo predominante, sendo que $62 \%$ dos docentes consideraram sua formação boa, muito boa ou excelente. Deve-se salientar, porém, que 38\% dos docentes consideram que sua formação foi regular, fraca ou inexistente (Figura 1B), o que é bastante similar ao encontrado em relação à percepção que relataram sobre sua formação nos cursos de Graduação. 
Figura 1 - Percepção dos docentes sobre a sua formação pedagógica inicial
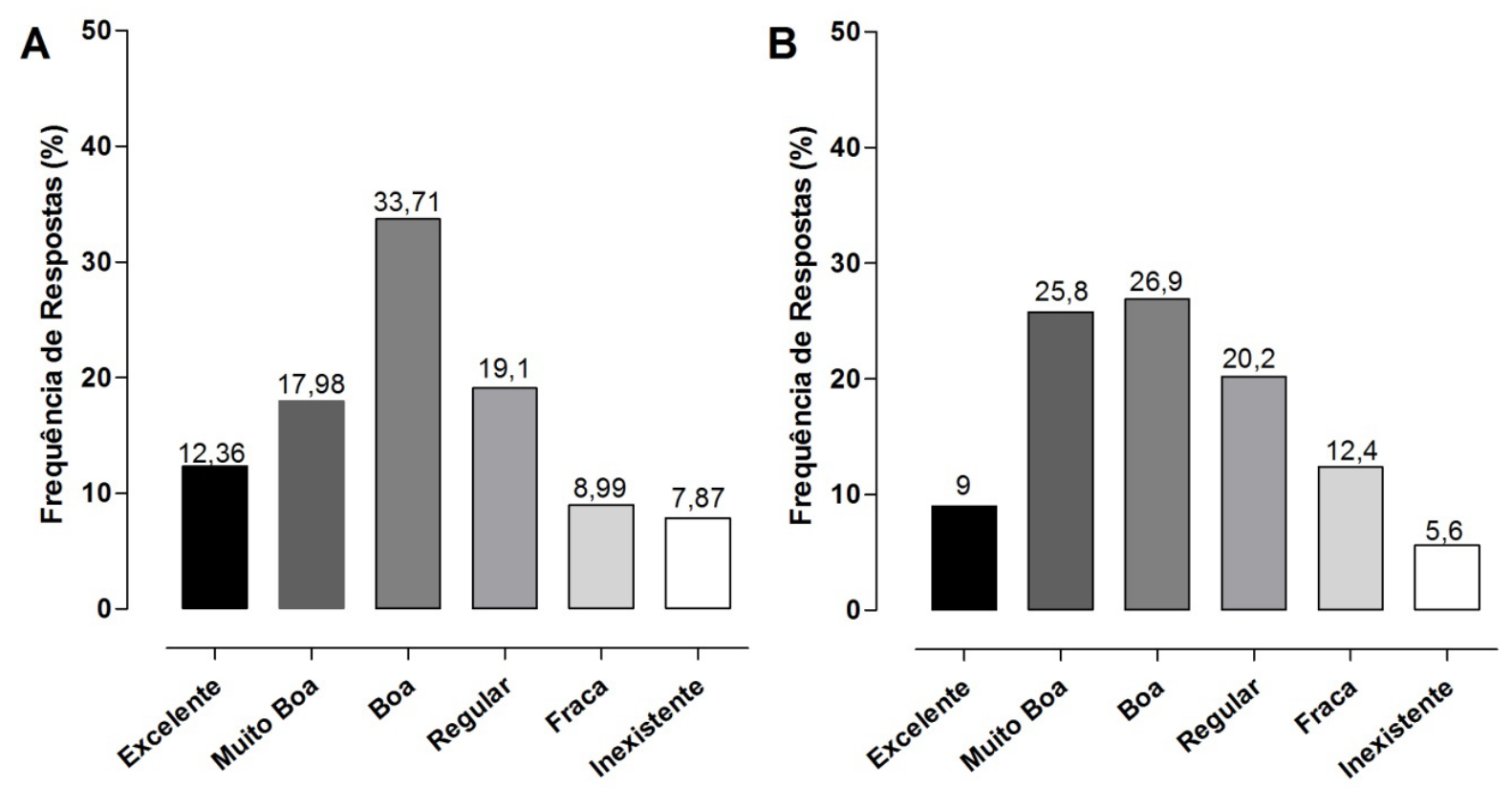

Fonte: Figura elaborada pelas pesquisadoras (2018). Graduação (A) e Pós-Graduação (B). Perguntas: A. Você considera que sua formação, no periodo da Graduação, quanto aos aspectos didático-pedagógicos foi. B. Você avalia que sua formação didático-pedagógica, capacitando-o para atuar como professor ao final do curso de Pós-Graduação foi:

Buscou-se esclarecer se a percepção positiva dos docentes em relação a sua formação pedagógica também era compartilhada pela coordenação dos PPGs e observou-se que mais da metade dos coordenadores (54.5\%) consideram a formação didático-pedagógica dos seus docentes permanentes muito boa. Outros $36,4 \%$ a consideram boa e 9,1\% a consideram fraca. Aparentemente, os coordenadores avaliam a formação pedagógica dos docentes com mais otimismo do que os próprios docentes (90,9\% dos coordenadores a consideram boa ou muito boa). Deve-se considerar a possibilidade de que o coordenador tenha algum constrangimento em avaliar de forma negativa a formação de seus docentes. Porém, é provável que eles não tenham refletido sobre isso anteriormente, como o que ocorre com a comunidade acadêmica em geral, especialmente nas IES públicas, mais envolvidas com as atividades de pesquisa (PACHANE; PEREIRA, 2004; ZABALZA; VICTÓRIA, 2018).

\section{Participação dos docentes em atividades de formação continuada}

Considerando que a formação continuada poderia contribuir para preencher lacunas da formação inicial, buscou-se investigar se os docentes participaram ou não desse tipo de atividade nos últimos dois anos. A Figura 2 mostra que $67 \%$ dos docentes não participaram ou participaram apenas uma vez em atividades de formação continuada. Uma pequena parte (8\%) dos docentes participou mais de cinco vezes nesse tipo de atividade. 
Figura 2 - Participação dos docentes em atividades de formação continuada

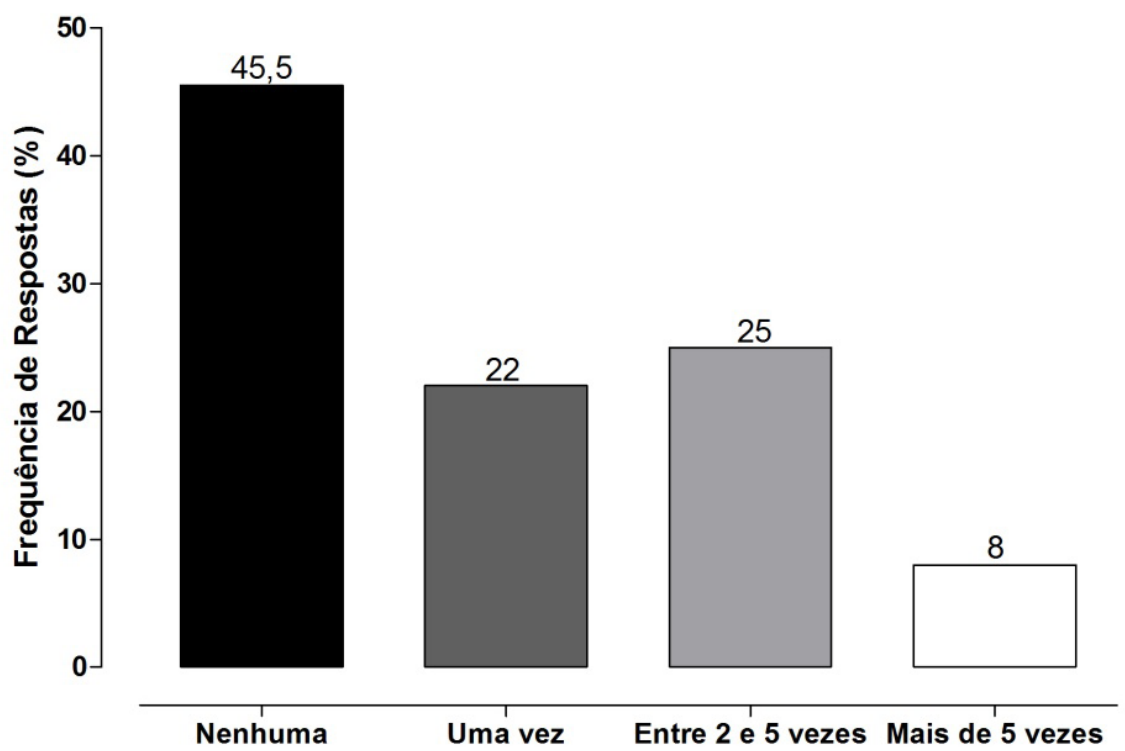

Fonte: Figura elaborada pelas pesquisadoras (2018). Pergunta: Quantas vezes você participou de atividades de formação continuada abordando questões didático-pedagógicas, nos últimos dois anos?

Para entender por que um percentual tão alto de docentes não participa das atividades de formação continuada, foi investigada a participação nessas atividades dos docentes que consideram que sua formação pedagógica foi regular, fraca ou inexistente, nos cursos de Pós-Graduação. Desses docentes, 67\% não participaram de atividades de formação continuada ou participaram apenas uma vez, indicando que não há relação entre buscar a formação continuada e a percepção da má qualidade de sua formação inicial.

Outra hipótese é de que os docentes não buscam formação continuada porque consideram que sua atuação é satisfatória. Assim, foi verificado qual a percepção que os docentes que não buscam formação continuada têm sobre sua atuação docente, e encontrou-se que $85 \%$ desses docentes avaliam sua atuação docente como boa, muito boa ou excelente, o que indica que esta hipótese pode ser um dos fatores que justifica esse resultado.

\section{Percepção dos docentes sobre seu desempenho didático-pedagógico}

Avaliando as respostas de todos os docentes que participaram da pesquisa, obteve-se uma avaliação geral boa sobre seu desempenho. $\mathrm{Na}$ Figura 3, observa-se que apesar das diferenças na formação inicial e continuada, a maioria dos docentes considera sua atuação pedagógica satisfatória: boa (33\%), muito boa (49\%) ou excelente (12,4\%)

Buscando esclarecer se o baixo percentual de participação em atividades de formação continuada poderia refletir uma percepção de bom desempenho, e por isso o docente não consideraria necessário aprimorar sua formação, investigou-se esse aspecto. Dos docentes que não participaram em atividades de formação continuada ou participaram apenas uma vez (59 docentes), 95\% consideram seu desempenho bom, muito bom ou excelente, o que confirmaria esta hipótese. Porém, surpreendentemente, 93\% dos que participaram duas ou mais vezes na formação continuada (29 docentes) avaliam seu desempenho como bom, muito bom ou excelente. Esses dados fazem pensar que talvez essa não seja a única razão para o baixo percentual de docentes que participam de atividades de formação continuada.

Assim, aparentemente, não se pode confirmar a hipótese de que os docentes não participam de atividades de formação continuada porque consideram que não precisam, uma vez que seu 
desempenho didático-pedagógico é bom. Ou seja, não é possivel, com os dados coletados nesta pesquisa, concluir sobre as motivações dos docentes para buscar ou não complementar sua formação didático-pedagógica. Além disso, não se conhece as características de cada instituição e de cada PPG, a oferta de atividades de formação, as prioridades institucionais e pessoais de cada docente etc. A atividade docente é complexa e envolve uma série de valores e prioridades, determinantes contextuais que exigiriam uma análise mais detalhada, a qual está fora do objetivo deste trabalho (PIMENTA; ANASTASIOU, 2002; BOLZAN; IZAIA, 2010; VEIGA, 2005).

$\mathrm{Na}$ falta de uma formação pedagógica institucionalizada, o docente acaba se formando na prática ajustando-se, basicamente, a valores, crenças e representações sociais em torno do que é ser professor, construídas ao longo de sua história de vida familiar e escolar, bem como a partir de suas interações com seus pares (ESTRELA et al., 2014). Segundo Grillo et al. (2008) por desconhecimento do conjunto de saberes que constituem a docência, o docente universitário tende a fundamentar sua prática pedagógica em modelos de professores que teve durante o periodo escolar ou em sugestões dadas por colegas mais experientes ou, ainda, na representação de professor, difundida na sociedade ocidental. Dito de outro modo, os docentes organizam seu trabalho usando como referencial o "senso comum pedagógico", segundo o qual o domínio de uma área específica do saber veiculado nos conteúdos escolares é condição suficiente para ser professor, ou ainda, que os conteúdos de ensino, articulados a procedimentos ensinados pela Didática possibilitam ao docente dar conta da complexidade e das exigências do cotidiano da aula universitária, assegurando um bom desempenho.

Figura 3 - Percepção dos docentes sobre seu desempenho didático-pedagógico

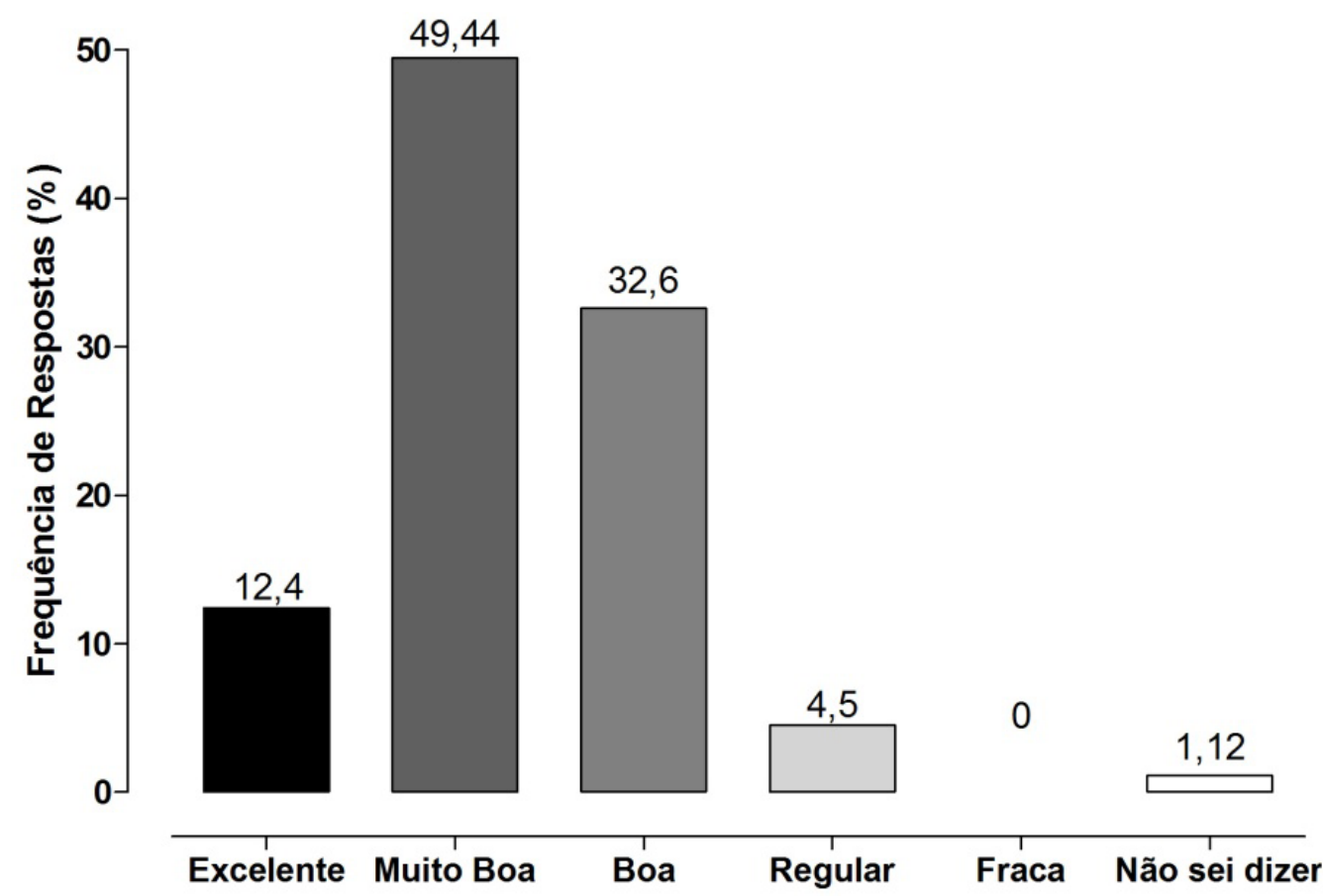

Fonte: elaborada pelas pesquisadoras (2018).

Pergunta: Você considera que sua atuação como docente é:

Conforme descrito por Pimenta e Anastasiou (2002), a profissão de professor tem caráter dinâmico como prática social, se transforma adquirindo novas características para responderem a novas demandas da sociedade. A identidade se constrói pelo significado que cada 
professor confere à atividade docente com base nos seus valores, história de vida, saberes, etc., assim como mediante sua rede de relações com outros professores, nas instituições de ensino, nos sindicatos e outros agrupamentos. Portanto, tem papel fundamental na construção da identidade docente o significado social que os professores atribuem a si mesmos e à educação (CUNHA; DINIZ-PEREIRA, 2017; TARDIF, 2002; VEIGA, 2014).

\section{Percepção do PPG e dos pós- \\ graduandos sobre a atuação pedagógica dos docentes}

Apesar das diferenças na formação inicial e continuada, 94.5\% dos docentes considera seu desempenho didático-pedagógico bom, muito bom ou excelente. Isso pode refletir uma excelente formação, e realmente um desempenho muito bom, ou poderíamos estar encontrando uma autoavaliação superestimada. Para investigar esse aspecto, foi avaliado se os pós-graduandos e os coordenadores dos Programas de PósGraduação tinham a mesma percepção relatada pelos docentes sobre o seu desempenho. Dentre os coordenadores, a maior parte ( $91 \%$ ) considera a atuação pedagógica dos docentes como frequentemente satisfatória e $9 \%$ considera que essa atuação é sempre satisfatória. Ou seja, uma avaliação muito positiva. É compreensivel que os coordenadores não queiram depor contra a atuação de seus docentes, mas essa avaliação parece improvável. Talvez isso esteja refletindo apenas o desconhecimento dos coordenadores ou o fato de não haver reflexão no âmbito da Pós-Graduação sobre a atuação dos docentes.

E o que dizem os alunos? Dos 273 alunos, $60 \%$ considera que a atuação didática e pedagógica dos docentes é frequentemente ou sempre satisfatória. É importante observar, que não é desprezivel o percentual de 39\% dos pós-graduandos que consideram a atuação de seus professores às vezes ou raramente satisfatória. Para entender melhor a avaliação dos pós-graduandos, os dados foram estratificados de acordo com a etapa do curso em que os respondentes se encontravam (Tabela 1). É interessante observar que essa avaliação varia um pouco dependendo da fase do curso e se o aluno cursa mestrado ou doutorado. Aparentemente esta avaliação se torna menos positiva ao longo do curso. Ou seja, no início do mestrado temos $80 \%$ de alunos considerando o desempenho dos docentes frequentemente ou sempre satisfatório. $\mathrm{Na}$ metade final do mestrado, esse número cai para $60 \%$. Nos primeiros dois anos de doutorado, temos 56\% dos alunos considerando satisfatório o desempenho dos docentes e este número cai para 49\% na segunda metade do doutorado. Estes dados revelam que, à medida que os alunos se inserem no sistema da Pós-Graduação, se tornam mais criticos e seus critérios de avaliação se aprimoram, o que é um fator positivo a respeito da sua formação.

TABELA 1 - Percepção dos alunos sobre a atuação didático-pedagógica de seus professores ao longo da Pós-Graduação

\begin{tabular}{|c|c|c|c|c|}
\hline & $n$ & $\begin{array}{c}\text { Sempre } \\
\text { satisfatória }\end{array}$ & $\begin{array}{l}\text { Frequentemente } \\
\text { satisfatória }\end{array}$ & Total \\
\hline Mestrado inicial & 59 & $22 \%$ & $57,6 \%$ & $80 \%$ \\
\hline Mestrado final & 55 & $9,1 \%$ & $50,9 \%$ & $60 \%$ \\
\hline Doutorado inicial & 86 & $9,3 \%$ & $46.5 \%$ & $56 \%$ \\
\hline Doutorado final & 73 & $8,2 \%$ & $41,1 \%$ & $49 \%$ \\
\hline
\end{tabular}

Fonte: Figura elaborada pelas pesquisadoras (2018). $n$ = número de pós-graduandos. 
Por outro lado, se quase a metade dos alunos não considera satisfatória a atuação dos docentes e quase todos os docentes consideram sua atuação satisfatória, algo precisa ser revisto. Os alunos terão uma exigência maior ou uma expectativa muito alta que acaba sendo frustrada diante dos docentes? Ou os docentes têm uma exigência menor? Será que como alunos eles teriam a mesma opinião sobre o desempenho dos docentes? Será que os docentes refletem sobre isso? Ou os alunos pensam mais sobre isso porque vivem o outro lado da questão? E estes alunos, como atuarão como docentes no futuro? Serão capazes de fazer sua própria reflexão e buscar uma atuação melhor ou apenas repetirão o padrão aprendido com seus mestres?

\section{Percepção dos docentes sobre a influência de sua prática docente na formação pedagógica dos pós-graduandos}

Para compreender até que ponto os docentes têm consciência de que grande parte da atuação docente no Ensino Superior se dá de acordo com os padrões e modelos que o docente conheceu na sua formação, investigou-se o que os mesmos pensam sobre isso. A maior parte dos docentes $(61,8 \%)$ considera que sua atuação didático-pedagógica influencia muito a formação pedagógica dos pós-graduandos. Um percentual menor, mas importante, de 25,8\% dos docentes considera que sua atuação influencia pouco a formação pedagógica dos pós-graduandos. É interessante observar que $8 \%$ dos docentes não souberam responder esta pergunta. Aproximadamente $4 \%$ opinam que sua atuação não influencia a formação dos alunos.

Para verificar se os Programas de PósGraduação estão oferecendo um ambiente propicio para a formação didático-pedagógica de seus alunos, investigou-se como se dá a formação pedagógica dos pós-graduandos e qual a percepção da comunidade acadêmica dos PPGs sobre essa formação.

\section{Formação pedagógica dos pós-graduandos}

Perguntados sobre como se dá a formação pedagógica dos pós-graduandos, os coordenadores informaram que a formação do mestrado e do doutorado é similar. No mestrado, há predomínio de estágios supervisionados com atuação em salas de aula da Graduação (72,7\%), seguidos pelo acompanhamento de professores em disciplinas de curso de Graduação (54.5\%) e auxilio em aulas práticas (45,5\%). As características desse tipo de coleta de dados não permitiram que o detalhamento das atividades fosse maior, inclusive a frequência com que as atividades ocorrem, quais são obrigatórias etc. Porém, nota-se que os alunos estão envolvidos em várias atividades que contribuem para sua formação didático-pedagógica.

Quanto à formação pedagógica dos alunos de doutorado, os percentuais não são muito diferentes dos encontrados no mestrado. Porém, observa-se que os estágios sem supervisão aumentam de 9,1\% no mestrado para $18,2 \%$ no doutorado. As outras atividades citadas, incluem aulas e discussões de textos sobre práticas pedagógicas (27,3\%), participação e organização de Curso de Férias, coorientação de alunos de Iniciação Científica. Também foi relatado que técnicas didáticas fazem parte do programa de algumas disciplinas. Aparentemente, essas atividades não são acompanhadas de uma reflexão coletiva sobre a atividade docente, uma vez que aproximadamente $40 \%$ dos docentes refere que não sabe se sua atuação pedagógica influencia a formação dos pós-graduandos ou acha que não influencia.

Embora o estágio didático possa ocorrer de forma solitária e com pouco apoio do professor da disciplina ou do orientador, sem dúvida é um espaço para a prática e reflexão sobre as atividades docentes. Segundo Martins e Cavalcante (2014) o estágio didático deve fornecer elementos capazes de promover uma ruptura no paradigma dominante no Ensino Superior, no qual o professor é concebido como detentor do conhecimento e sua prática pedagógica acima de qualquer questionamento e de que o conhecimento dos conteúdos específicos é suficiente para o exercício 
da docência. Alguns autores têm estudado a importância de estágios de docência (exigência para bolsistas CAPES, Portaria 52/2002) para a formação dos pós-graduandos e salientam que em alguns PPGs há disciplinas que contribuem para essa formação (QUADROS et al., 2012) e outros em que o estágio é parte de uma ou mais disciplinas. Se não for bem planejado e acompanhado de reflexão, o estágio didático corre o risco de se tornar mera exigência burocrática a ser cumprida (VIEIRA; MACIEL, 2010), ou de ser usado como modo de "preparação para concurso", ou redução da carga horária do docente.

\section{Percepção sobre a qualidade da formação pedagógica dos pós-graduandos}

Para investigar como a comunidade acadêmica avalia a formação pedagógica que oferece aos pós-graduandos, foi perguntada a opinião dos docentes e dos coordenadores sobre este tema. Entre os docentes, 51,7\% considera que a formação pedagógica dos pós-graduandos é boa (26\%), muito boa (25\%) ou excelente ( $1 \%$ ) e $46 \%$ considera essa formação regular (33\%) ou fraca (13,5\%). Entre os coordenadores, 70\% considera que a formação pedagógica oferecida aos pós-graduandos é boa ou muito boa (muito boa: $36,4 \%$; boa: $36,4 \%$; regular: 18,2\%; fraca: 9,1\%), e $27 \%$ dos coordenadores a considerem regular ou fraca. Aparentemente os docentes são mais criticos que os coordenadores quanto à formação dos pós-graduandos.

A maior parte dos pós-graduandos considera sua formação didático-pedagógica boa, muito boa ou excelente $(66,7 \%)$. Porém, não podem ser desprezados os 32\% que a consideram regular ou fraca (Figura $4 \mathrm{~A}$ ). Nas manifestações livres, muitos alunos expuseram sua insatisfação com a necessidade de publicar tanto e não ter oportunidade de investir mais na formação pedagógica. Os docentes também expressaram essa preocupação (dados não mostrados).

Observa-se, na Figura 4B, que os percentuais de aprovação da formação para atuar como pesquisador são maiores do que os da formação como professor, ou seja, 93\% dos alunos consideram que sua formação como pesquisador é excelente, muito boa ou boa.

Figura 4 - Percepção dos pós-graduandos sobre a sua formação
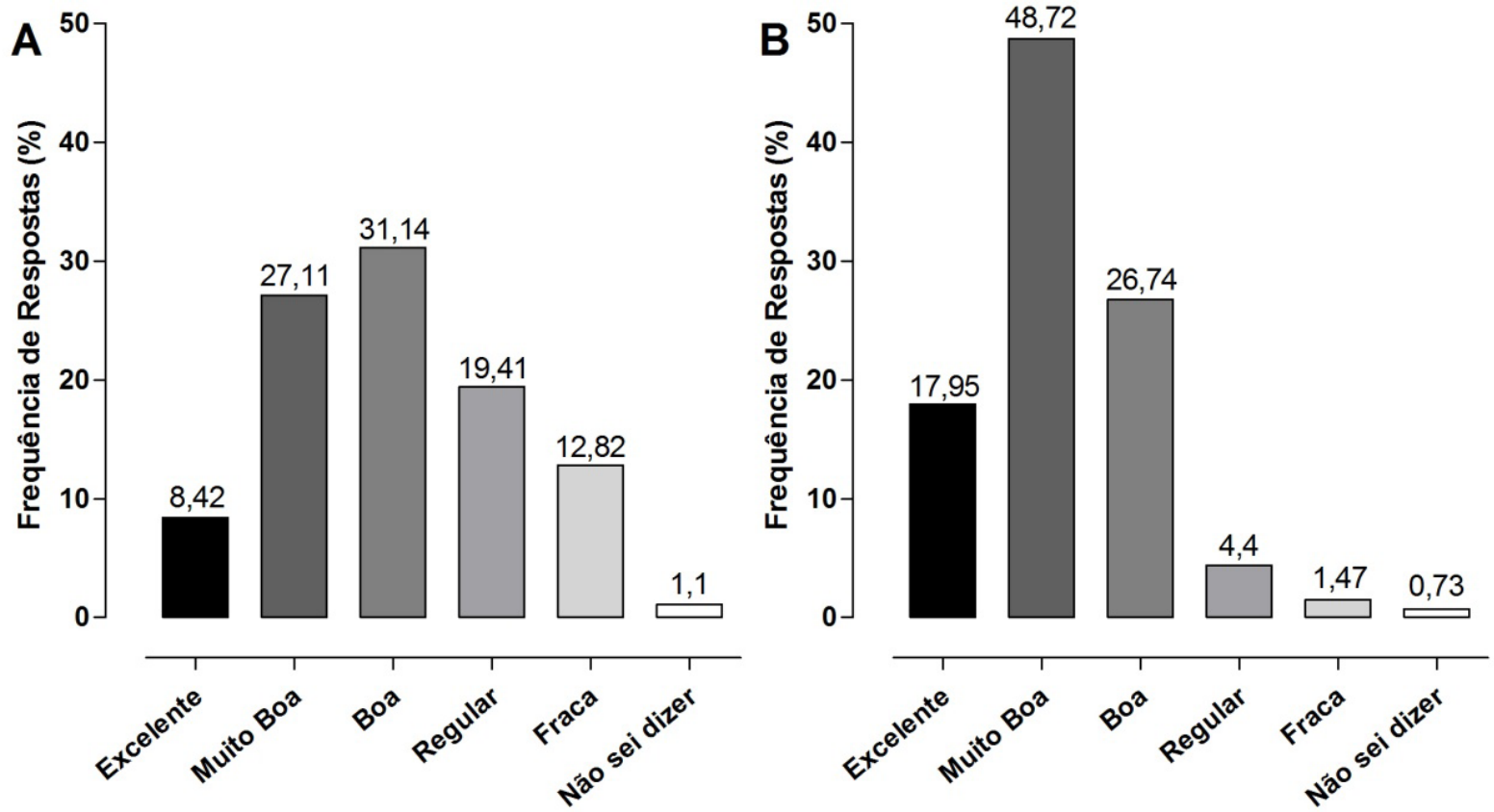

Fonte: Figura elaborada pelas pesquisadoras (2018). Para atuação como professor (A) e como pesquisador (B). Pergunta: A. Você avalia que sua formação didática e pedagógica, para atuar como professor, ao final deste Curso de Pós-Graduação será. B. Você avalia que sua formação para atuar como pesquisador, ao final deste Curso de Pós-Graduação, será: 
Considerando que a formação no nivel da PósGraduação stricto sensu é relativamente longa, optou-se por avaliar se o pós-graduando muda sua avaliação a respeito da própria formação ao longo do curso. A Tabela 2 mostra como ocorre essa variação para alunos de mestrado e doutorado, na primeira ou segunda metade do curso. Observa-se uma redução da avaliação positiva sobre a formação, tanto pedagógica quanto como pesquisador, ao longo dos cursos de mestrado e doutorado. No inicio do mestrado, $78 \%$ dos alunos consideram sua formação pedagógica boa, muito boa ou excelente. No final do mestrado esse número cai para $65 \%$ e no final do doutorado chega a 60\%. Apesar disso, a aprovação dos alunos sobre sua formação como pesquisador varia de $97 \%$ no início do mestrado a $89 \%$ no final do doutorado. Aparentemente, o pós-graduando aprova sua formação como pesquisador durante todo o curso, permanecendo perto de $90 \%$ ao longo do mestrado e do doutorado.

TABELA 2 - Percepção dos alunos sobre sua formação para atuar como docente e como pesquisador, ao longo do mestrado e do doutorado

\begin{tabular}{lccccccccc}
\hline & \multicolumn{4}{c}{ Formação didático-pedagógica } & \multicolumn{3}{c}{ Formação como pesquisador } \\
\hline & n & Exc & MBoa & Boa & Total & Exc & MBoa & Boa & Total \\
\hline $\begin{array}{c}\text { Mestrado } \\
\text { inicial }\end{array}$ & 59 & 14 & 39 & 25 & $78 \%$ & 24 & 48 & 25 & $97 \%$ \\
$\begin{array}{c}\text { Mestrado final } \\
\begin{array}{c}\text { Doutorado } \\
\text { inicial }\end{array}\end{array}$ & 55 & 5 & 29 & 31 & $65.5 \%$ & 15 & 53 & 24 & $91 \%$ \\
$\begin{array}{c}\text { Doutorado } \\
\text { final }\end{array}$ & 73 & 8 & 26 & 31 & $65.5 \%$ & 12 & 55 & 30 & $97 \%$ \\
\hline
\end{tabular}

Fonte: Tabela elaborada pelas pesquisadoras (2018). $\mathrm{n}$ = número de alunos; Exc = excelente; MBoa = muito boa.

\section{Perspectiva de atuação profissional}

A Figura 5 mostra que aproximadamente a metade dos alunos gostaria de atuar tanto como professor quanto como pesquisador (53.5\%). Somando os que gostariam de atuar exclusivamente como pesquisador ou mais como pesquisador do que como professor, tem-se $15,4 \%$ dos alunos. Considerando aqueles que desejam atuar exclusivamente como professor ou mais como professor do que como pesquisador, tem-se 31\%. Esses percentuais de perspectiva de atuação profissional são indicativos da necessidade de que a formação didático-pedagógica dos pósgraduandos seja considerado algo prioritário nos Programas de Pós-Graduação, além do fato de que o mercado de trabalho para mestres e doutores inclui a atividade docente no Ensino, na grande maioria das oportunidades. Do total de docentes do Ensino Superior, a maior parte atua em IES privadas, principalmente em faculdades, onde a pesquisa não é obrigatória e as atividades de ensino são prioritárias (INEP, 2017).

É sabido que os PPGs são avaliados pela CAPES e que dependem dessa avaliação para manter seu conceito, obter recursos e garantir que tenha procura por pesquisadores e pós-graduandos. O que for valorizado na avaliação da Capes, certamente será valorizado nos PPGs. Para isso, seria importante que a comunidade acadêmica valorizasse a formação pedagógica dos pósgraduandos, uma vez que os comitês de avaliação da Capes são constituídos por pesquisadores/ docentes. Será que os atores das comunidades acadêmicas estudadas aqui valorizam a formação pedagógica dos pós-graduandos? 
Figura-5 - Perspectiva de atuação profissional dos pós-graduandos

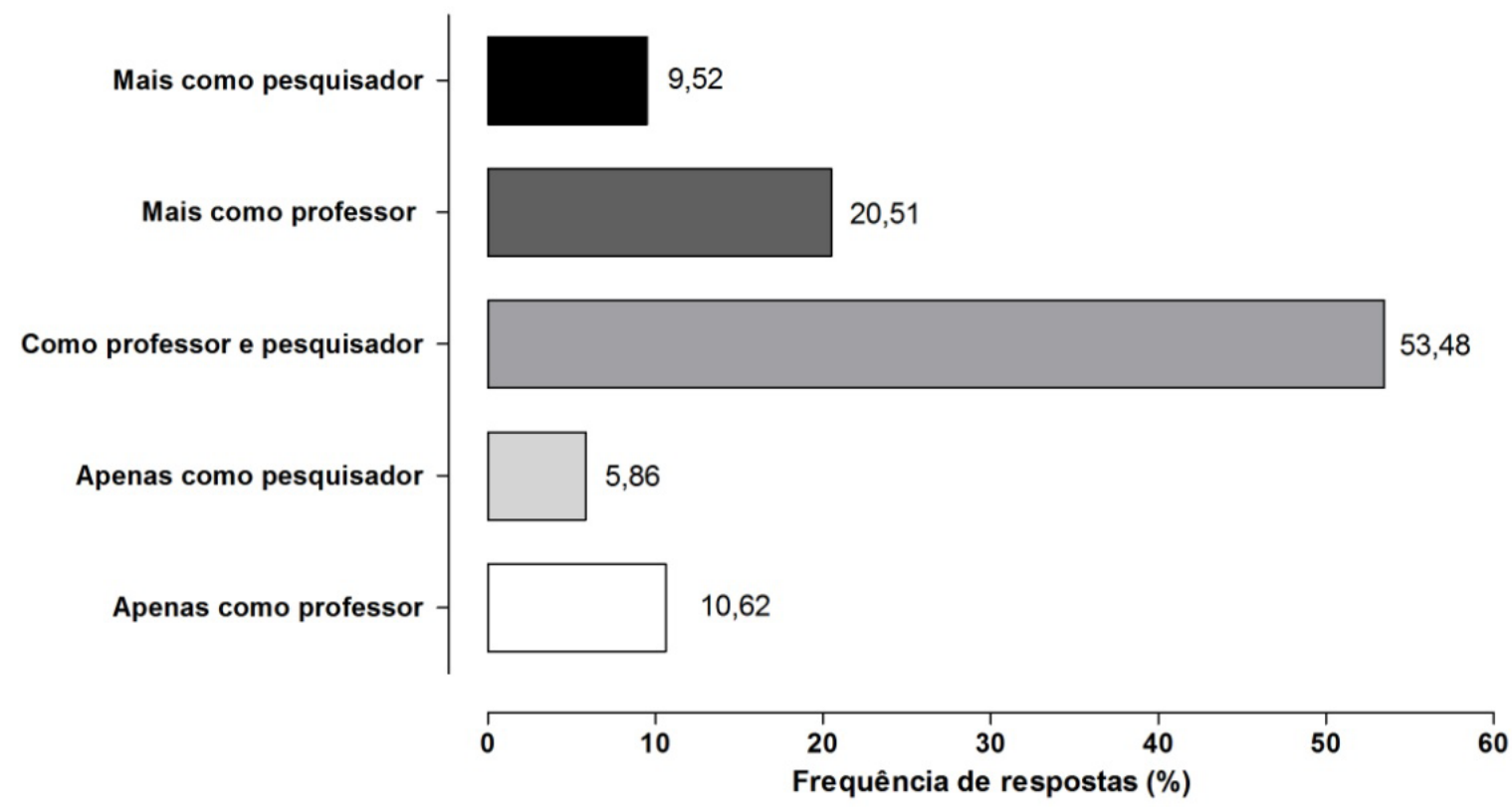

Fonte: Figura elaborada pelas pesquisadoras (2018). Pergunta: Você gostaria de atuar profissionalmente

\section{Importância dada à formação}

\section{pedagógica dos pós-graduandos}

Em relação ao valor dado pela comunidade acadêmica à formação pedagógica dos pósgraduandos, a maioria dos alunos $(76 \%)$ considera tão importante sua formação como pesquisador quanto como professor, $64 \%$ dos coordenadores também avaliam assim. Não é desprezivel o percentual de $36 \%$ dos coordenadores que considera a formação científica para atuar como pesquisador mais importante do que a formação pedagógica dos pós-graduandos. Porém, isso está de acordo com o que os coordenadores pensam sobre a avaliação da CAPES, a qual desconsidera a formação pedagógica (18\%) ou a considera menos importante do que a produção científica dos pós-graduandos ( $64 \%$ ). Chama atenção que cerca de $9.5 \%$ dos pós-graduandos considera sua formação pedagógica uma obrigação, embora a perspectiva de atuação profissional mostre que $31 \%$ dos pós-graduandos gostariam de atuar exclusivamente como professor ou mais como professor do que como pesquisador e 50\% com as duas atividades. Por outro lado, $11 \%$ dos alunos considera mais importante a formação pedagógica do que a de pesquisador.

Podemos concluir que, de uma maneira geral, os agentes envolvidos reconhecem a importância da formação pedagógica dos pós-graduandos, mas o sistema de Pós-Graduação como um todo não estimula o desenvolvimento de atividades que contribuam para essa formação. Também não foi possivel esclarecer com estes dados o significado de formação didático-pedagógica para cada um dos respondentes.

Corrêa e Ribeiro (2013) já ressaltavam a importância da valorização do ensino na universidade e a relevância da formação do capital pedagógico na Pós-Graduação stricto sensu, em meio a um ambiente competitivo e voltado quase exclusivamente ao acúmulo de capital científico. A carreira do cientista é essencialmente orientada para a obtenção do reconhecimento de sua comunidade pelos trabalhos que realiza, suas pesquisas e publicações; o ensino, e mais particularmente o ensino ao nivel de Graduação, é visto como um estorvo e um desperdício de tempo em relação a suas atividades mais importantes (SCHWARTZMAN, 2008). 


\section{Percepção da atividade docente e valor} dado em comparação com atividades de pesquisa

Para esclarecer como os docentes percebem suas atividades docentes, foi incluída a pergunta: Você diria que suas atividades como docente são: gratificantes, desafiadoras, indiferentes, uma obrigação, tediosas, outra? Do total de docentes que participaram da pesquisa, 55\% consideram as atividades docentes gratificantes e 40\% as consideram desafiadoras. Isso mostra que a maioria dos docentes que participaram da pesquisa gosta de ser professor. Esses dados são animadores e reforçam a ideia inicial de que esses professores seriam receptivos à reflexão sobre sua prática docente e talvez tivessem disponibilidade de participar de atividades de formação pedagógica proporcionadas por sua IES ou mesmo por seu PPG.

Como o professor vive o dilema de ter que se dividir entre as atividades de pesquisa, de ensino, entre outras, foi incluida uma pergunta para avaliar a importância que esses docentes dão para as atividades de ensino em comparação com as de pesquisa. Os docentes valorizam sua atividade docente, sendo que $86 \%$ do total de docentes consideram as atividades de ensino tão importantes quanto as atividades de pesquisa. Sabe-se que a produção científica é o fator mais valorizado pela CAPES e isto é claramente percebido pelos coordenadores. Sabendo da importância dada pela CAPES à produção científica, avaliamos se aqueles PPGs com melhor avaliação na CAPES tinham uma percepção diferente em relação à dicotomia professor/pesquisador nas suas atribuições formativas. Todos os coordenadores de Cursos 5 , 6 e 7 consideram a formação pedagógica menos importante do que a formação de pesquisadores, mostrando-se totalmente alinhados com as recomendações da CAPES.

\section{Considerações finais}

Sabe-se que os professores universitários e os pós-graduandos possuem excesso de tarefas a cumprir, sendo as atividades de pesquisa e a produção científica as mais valorizadas pelos órgãos avaliadores (Capes) e agências de fomento (CNPq, Fundações Estaduais etc.). Dando eco aos demais niveis do sistema de Pós-Graduação, as universidades também valorizam e estimulam a produção científica, preocupadas com sua classificação em rankings nacionais e internacionais. Nesse contexto, a formação pedagógica e o desempenho didático dos professores universitários é algo considerado menos importante. Logo, a formação de futuros docentes também não é considerada prioridade. Zabalza e Vitória (2018, p. 135) expressam claramente essa questão "Não apenas nos discursos e nos documentos, mas na forma como se estabelecem as prioridades, que importância tem a docência no conjunto do funcionamento de uma universidade?"

Conclui-se que, de uma maneira geral, a comunidade acadêmica reconhece a importância da formação pedagógica dos pós-graduandos e da atividade docente, porém há pouca valorização da formação continuada. Sugere-se que os PPGs proporcionem uma reflexão critica sobre a formação pedagógica dos pós-graduandos e a valorização da atuação docente, uma vez que o sistema como um todo não estimula o desenvolvimento de atividades que contribuam para essa formação. Além disso, a implantação pelas IES de formação continuada sistemática parece ser um ótimo caminho para melhorar a qualidade do Ensino Superior. Cabe também aos professores abrirem essa fronteira e começarem a valorizar sua atividade, em nome da qualidade do Ensino Superior.

\section{Referências}

BOLZAN, D. P. V.; ISAIA, S. M. A. Pedagogia universitária e aprendizagem docente: relações e novos sentidos da professoralidade. Rev. Diálogo Educ. Curitiba, v. 10, n. 29, p. 13-26, jan./abr. 2010, https:// doi.org/10.7213/rde.v10i29.3043

BRASIL,1996. Lei $\mathbf{n}^{\circ} \mathbf{9 . 3 9 4}$, de 20 de dezembro de 1996. Brasilia. Disponivel em: http://www.planalto.gov. br/ccivil_03/Leis/L9394.htm. Acesso em: 20 nov 2018.

CAPES/PNPG. I Plano Nacional da Pós-Graduação (PNPG). Disponivel em: http://Www.capes.gov. br/images/stories/download/editais/I_PNPG.pdf. Acesso em: 20 nov. 2018. 
CARDOSO, M. R. G. O professor do Ensino Superior hoje: perspectivas e desafios. Cadernos da Fucamp Monte Carmelo, v. 15, n. 23, p. 87-106, 2016

COLTHORPE, K. L.; ABE, H.; AINSCOUGH, L. How do students deal with difficult physiological knowledge? Advances in Physiology Education, Rockville, v. 42, p. 555-564, 2018. https://doi.org/10.1152/advan.00102.2018

CORRÊA, G. T; RIBEIRO, V. M. B. A formação pedagógica no Ensino Superior e o papel da pós-graduação stricto sensu. Educação e Pesquisa, São Paulo, v. 39 , n. 2, p. 319-334, 2013

CUNHA, E. R.; DINIZ-PEREIRA, J. E. Docência no Ensino Superior: Uma breve revisão das pesquisas sobre a formação docente e a prática pedagógica do professor universitário. In: LOPES, J. G. S.; MASSI, L. (org.). Aprendizagens da docência no Ensino Superior: desafios e perspectivas da Educação em Ciências. 1.ed. São Paulo: Livraria da Física, 2017. p. 27-52.

ESTRELA, J. M. S.; SIMÕES, A. C.; HESPANHOL, A. C. F. As competências profissionais práticas, dos docentes de disciplinas especificas nos cursos de engenharia. In: COBENGE, Engenharia, múltiplos saberes e atuação, Juiz de Fora, MG, 2014.

FALEIROS, F. et al. Uso de questionário online e divulgação virtual como Estratégia de coleta de dados em estudos cientíicos. Texto Contexto Enferm, Florianópolis, v. 25, n. 4, e3880014, 2016.

GIL, A. C. Didática do Ensino Superior. São Paulo: Atlas S.A., 2015.

GRILLO, M. C. et al. A gestão da aula universitária na PUCRS. Porto Alegre: ediPUCRS, 2008.

INSTITUTO NACIONAL DE ESTUDOS E PESQUISAS DE EDUCAČ̃̃O ANISIO TEIXEIRA - INEP - (Brasil), Censo Da Educação Superior, 2017, Disponivel em: http://portal.inep.gov.br/web/guest/sinopses-estatisticas-da-educacao-superior. Acesso em: 12 ago. 2018

LOURENÇO, C. D. S.; LIMA, M. C.; NARCISO, E.R.P. Formação pedagógica no Ensino Superior: o que diz a legislação e a literatura em Educação e Administração? Avaliação (Campinas); Sorocaba, v. 21, n. 3. p. 691-717, 2016. https://doi.org/10.1590/S141440772016000300003

MARTINS, M. M. M. C.; CAVALCANTE, M. M. D. Estágio de docência na formação de pós-graduandos stricto sensu à luz da pedagogia universitária. In: Didática e Prática de Ensino na relação com a Formação de Professores, ENCONTRO NACIONAL DE PRÁTICA DE ENSINO, 17, Editora UECE, Livro 2, 2014.

MICHAEL, J. What makes physiology hard for students to learn? Results of a faculty survey. Advances in Physiology Education, Rockville, v. 31, p.34-40, 2007. https://doi.org/10.1152/advan.00057.2006

OLIVEIRA, A. R.; MELLO, C. F. Indicadores para a avaliação da produtividade em pesquisa: a opinião dos pesquisadores que concorrem a bolsas do CNPq na área de Biociências. Revista Brasileira de Pós-Graduação, Brasilia, v. 11, n. 25, p. 657-678, 2014.
PACHANE, G. G.; PEREIRA, E. M. A. A importância da formação didático-pedagógica e a construção de um novo perfil para docentes universitários. Revista Ibero-Americana de Educación, Madri, v. 35, n. 1, p. 1-13, 2004.

PIMENTA, S. G.; ANASTASIOU, L. G. C. Docência no Ensino Superior. 5. ed. São Paulo: Cortez, 2002 (Coleção Docência em formação, v. 1).

MEC/PNE. Planejando a Próxima Década. Disponivel em: http://pne.mec.gov.br/Acesso em: nov. 2018.

QUADROS, A. L. et al. Professor de Ensino Superior: o entendimento a partir de narrativas de pós-graduandos em química. Educação e Pesquisa, São Paulo, v. 38, n. 2, p. 389-402, abr./jun., 2012.

SCHWARTZMAN, S. Por uma Política Cientíica. In: Ciência, Universidade e Ideologia: A Política do Conhecimento. Rio de Janeiro: Centro Edelstein de Pesquisas Sociais, 2008. p.39-57.

SILVEIRA, H.E. Docência Universitária: Apontamentos e reflexões sobre a formação de professores. In: LOPES, J.G.S; MASSI, L. (org.). Aprendizagens da docência no Ensino Superior: desafios e perspectivas da Educação em Ciências. 1.ed. São Paulo: Livraria da Física, 2017. p. 53-68

TARDIF, M. Saberes docentes e formação profissional, 17. ed. Petrópolis: Vozes, 2002.

VALENTE, G. S. C.; VIANA, L. O. O ensino de nível superior no Brasil e as competências docentes: Um olhar reflexivo sobre esta prática. Práxis Educacional, Vitória da Conquista, v. 6, n. 9. p. 209-226, jul./dez. 2010.

VEIGA, I. P. A. Docência Universitária na Educação Superior. In: SIMPÓSIO INEP, 6., 2005, Brasilia, p. 1-11.

VEIGA, I. P. A. Formação de professores para a Educação Superior e a diversidade da docência. Rev. Diálogo Educ., Curitiba, v. 14, n. 42, p. 327-342, maio/ago, 2014

VIEIRA, R. A.; MACIEL, L. S. B. Estágio de docência prescrito pela capes: tensões e desafios. Quaestio, Sorocaba, v. 12, p. 47-64, nov. 2010.

ZABALZA, M.; VITÓRIA, M.I.C. Una cuestión previa:¿Centralidad o marginalidad de la docencia en la Universidad? In: ZABALZA, M.B.; MENTGES, M., VITÓRIA, M.I.C. (org.). Engagement na Educação Superior. Porto Alegre: EDIPUCRS, 2018. p.135-154.

\section{Maria Flavia Marques Ribeiro}

Doutora em Fisiologia, Professora Titular do Departamento de Fisiologia, Universidade Federal do Rio Grande do Sul, Porto Alegre, Rio Grande do Sul, Brasil (UFRGS)

\section{Gislaine Alves de Oliveira}

Doutoranda do Programa de Pós-Graduação em Ciências Biológicas: Fisiologia, Universidade Federal do Rio Grande do Sul (UFRGS, Porto Alegre, RS, Brasil). 


\section{Elaine Turk Faria}

Doutora em Educação; professora titular aposentada

da Faculdade de Educação da Pontificia Universi-

dade Católica do Rio Grande do Sul, Brasil (PUCRS)

Porto Alegre, RS, Brasil.

\section{Endereço para correspondência}

Maria Flavia Marques Ribeiro

Universidade Federal do Rio Grande do Sul

Rua Sarmento Leite, 500, 2. ${ }^{\circ}$ andar

90050170

Porto Alegre, RS, Brasil 